\title{
The effect of prophylactic surgery in survival and HRQoL in appendiceal NEN
}

\author{
Krystallenia I. Alexandraki ${ }^{1}$ - Gregory Kaltsas ${ }^{1}$ - Simona Grozinsky-Glasberg ${ }^{2} \cdot$ Kira Oleinikov $^{2} \cdot$ Beata Kos-Kudła $^{3}$. \\ Angelika Kogut ${ }^{3} \cdot$ Rajaventhan Srirajaskanthan $^{4,5} \cdot$ Michail Pizanias $^{6} \cdot$ Kalliopi-Anna Poulia $^{7} \cdot$ Clara Ferreira $^{8}$. \\ Martin O. Weickert ${ }^{9,10,11} \cdot$ Kosmas Daskalakis $\mathbb{1}^{1,12}$
}

Received: 26 March 2020 / Accepted: 15 May 2020 / Published online: 24 July 2020

(c) The Author(s) 2020

\begin{abstract}
Background/aims Long-term outcomes are understudied in patients with well-differentiated appendiceal neuroendocrine neoplasms (WD-ANENs). We aimed to evaluate the validity of currently applied criteria for completion prophylactic right hemicolectomy (pRHC) and determine its association with patient outcomes, including health-related quality of life (HRQoL).

Methods Eligible patients from five European referral centers were divided between those who underwent appendectomy alone and those who underwent completion pRHC. HRQoL EORTC-QLC-C30 questionnaires and cross-sectional imaging data were prospectively collected. Age- and sex-matched healthy controls were recruited for HRQoL analysis' validation. Results We included 166 patients (119 women [71.2\%]: mean age at baseline: $31 \pm 16$ years). Mean follow-up was $50.9 \pm$ 54 months. Most patients (152 [92\%]) had tumors $\leq 20 \mathrm{~mm}$ in size. Fifty-eight patients (34.9\%) underwent pRHC that in final analysis was regarded as an overtreatment in $38 / 58(65.5 \%)$. In multivariable analysis, tumor size $>20 \mathrm{~mm}$ was the only independent predictor for lymph node $(\mathrm{LN})$ involvement $(p=0.002)$. No mortality was reported, whereas 2-, 5- and 10-year recurrence-free survival in patients subjected to postoperative cross-sectional imaging $(n=136)$ was $98.5 \%, 97.8 \%$, and 97.8\%, respectively. Global HRQoL was not significantly impaired in patients with WD-ANEN compared with age- and sex-matched healthy individuals (median scores $0.83[0.08-1]$ vs $0.83[0.4-1]$, respectively; $p=0.929$ ). Among patients with WD-ANEN impaired social functioning $(p=0.016)$, diarrhea $(p=0.003)$ and financial difficulties $(0.024)$ were more frequently reported in the pRHC group.

Conclusions WD-ANEN is a low-malignant neoplasm with unconfirmed associated mortality, low recurrence rate, and overall preserved HRQoL. pRHC comes at a price of excessive surgery, functional HRQoL issues, and diarrhea. The value per se of a prophylactic surgical approach to patients with WD-ANENs $<20 \mathrm{~mm}$ is challenged.
\end{abstract}

Keywords Appendix $\cdot$ Carcinoid $\cdot$ Neuroendocrine tumor $\cdot$ Prophylactic surgery $\cdot$ Health-related quality of life

\section{Introduction}

A worldwide increase in the incidence of neuroendocrine neoplasms (NENs) has recently been described, including appendiceal NENs (ANENs) [1]. This increment is most

These authors contributed equally: Krystallenia I. Alexandraki, Gregory Kaltsas

Kosmas Daskalakis

kosmas.daskalakis@oru.se

Extended author information available on the last page of the article probably secondary to increased application of diagnostic procedures and widespread use of pathologic scrutiny of appendix specimens removed at appendectomy along with increased clinicians' awareness. However, many of these patients might have remained untroubled by tumor-related consequences, had the tumor not been detected.

Well-differentiated ANENs (WD-ANENs) are mainly of Grade 1 and commonly exhibit a benign clinical course with only few cases being reported with distant metastases [2, 3]. Therefore, ANEN standard treatment is surgery, which can be limited to the initial appendectomy or completed with a prophylactic right hemicolectomy (pRHC), with the latter potentially been associated with adverse consequences in terms of long-term health-related quality of life (HRQoL) 
impairment [4]. Contemporary guidelines suggest a rather aggressive surgical approach with completion pRHC as a treatment option for patients diagnosed with tumors $\geq 20 \mathrm{~mm}$ or tumors $10-20 \mathrm{~mm}$ in the presence of certain histopathological parameters [5, 6]. However, recent cohort studies and meta-analyses have questioned the validity of currently applied criteria for completion pRHC in WD-ANENs [2, 7-10]. Nevertheless, the association of indolent locoregional lymph node (LN) metastases with long-term patient outcomes has not been fully determined $[10,11]$. Hence, a more conservative strategy with an active surveillance approach following appendectomy to WD-ANEN patients with histopathological risk parameters has only lately been suggested pending confirmation from prolonged follow-up data [2, 12, 13].

Importantly, patient outcomes have been assessed in ANEN clinical studies, using mainly parameters, such as LN positivity at completion pRHC. However, apart from the yet undetermined survival benefit of a prophylactical surgical approach to these patients, a more comprehensive assessment of HRQoL aspects and prospective imaging confirmation of disease status is largely missing. In the era of a "less is more" approach and the possibility of performing likely unnecessary surgeries in patients with WDANENs, this study aimed to evaluate the rate of potentially unnecessary pRHCs in WD-ANEN patients and the validity of contemporary criteria. In addition, we aimed to evaluate whether certain histopathological parameters applied for completion surgery could predict locoregional LN status at pRHC; to determine the prognostic impact of LN metastases with regards to recurrence and survival outcomes; and to assess the range of HRQoL outcomes, and whether these vary depending on the type of surgery the patient received.

\section{Methods}

\section{Study design}

Data were extracted from the NEN databases of five collaborating European Neuroendocrine Tumor Society (ENETS) Centers of Excellence: the EKPA-Laiko Center, Athens, Greece; the ARDEN NET Center, University Hospitals Coventry and Warwickshire, NHS Trust, Coventry, UK (audit number 515/2019); the Neuroendocrine Tumor Unit, KHP ENETS Center of Excellence, King's College Hospital, London, UK; the Neuroendocrine Tumor Unit, Endocrinology and Metabolism Department, Hadassah-Hebrew University Medical Center, Jerusalem, Israel; and the Department of Endocrinology and Neuroendocrine Neoplasms, Department of Endocrinology and Pathophysiology, Medical University of Silesia, Katowice, Poland. We included only patients with a definite histopathological WD-ANEN diagnosis, with disease stage I-III.
Patients with goblet cell appendiceal tumors and tumors of mixed histopathology were excluded. In addition, patients operated upfront with more extensive bowel resections (small bowel resection, caecectomy, right hemicolectomy, or total colectomy) than appendectomy alone at the time of incidental WD-ANEN diagnosis for any indication (malignancy or benign conditions) were not included in this study.

The diagnoses were made between the 1 st of August 1992 and the 31st of July 2019, and patients were followed until death or September 15th, 2019. Cross-sectional imaging with abdominal magnetic resonance imaging (MRI) was prospectively obtained in patients with follow-up $>10$ years. As part of the study, participants were also asked to fill in a HRQOL EORTC-QLQ-C30 questionnaire [14]. HRQOL questionnaires were also obtained from 20 healthy control cases of age- and sex-matched individuals who did not have any abdominal surgery in their personal history, for comparison.

The study was conducted according to the 1975 Declaration of Helsinki and approved by the pertinent Human Research Ethics Committee of each institution. In the collaborating centers from UK, the study was officially registered as an audit. Written informed consent for the study was obtained from study participants. To ensure the quality of data reporting, we followed the STROBE statement [15].

At diagnosis, patients underwent cross-sectional imaging with either computed tomography (CT) scan or magnetic resonance imaging (MRI) of the abdomen. Each center followed the ENETS guidelines for completion pRHC following incidental diagnosis at appendectomy [5]. Subsequently, surveillance protocols with sequential crosssectional imaging of the abdomen with computed tomography (CT) or MRI were performed to assess disease recurrence (locoregional and/or at distant sites-mainly the liver) in lymph node positive WD-ANEN patients subjected to pRHC and also patients at high risk (i.e. tumor size $\geq 20 \mathrm{~mm}$, ANEN located in appendix base, grade 2, mesoappendiceal-, vascular-, lymph vessel-, and/or perineural invasion) not subjected to pRHC for reasons including other comorbidities and no consent, as per ENETS guidelines [5]. Due to cumulative exposure to irradiation with repetitive CT scanning, MRI was performed in most patients, particularly in younger and of fertile age [16]. In addition, although unproven, taken into consideration the life-long awareness of the potential of recurrence for WD-ANEN $>20 \mathrm{~mm}$ or $>10 \mathrm{~mm}$ with risk factors, different surveillance approaches with MRI at varying intervals were applied at each center also for patients who underwent a pRHC $[5,17]$. Tumor grade was determined from primary appendix specimens according to the Ki-67 proliferation index by a dedicated histopathologist at each center according to ENETS guidelines [5]. We used the 2017 WHO classification systems for grading 
gastro-enteropancreatic NENs [18]. For staging, we used the 8th edition of the American Joint Committee on Cancer (AJCC) [19].

We used the EORTC QLQ-C30 questionnaire developed by the European Organization for Research and Treatment of Cancer (EORTC) that is composed of multi-item functional subscales: physical, role, emotional, social and cognitive functioning; three multi-item symptom scales measuring fatigue, pain, and emesis; global health/quality of life subscale; and six single items assessing financial impact and symptoms such as dyspnea, sleep disturbance, appetite, diarrhea, and constipation [14]. Patients' responses were evaluated and summarized according to standard HRQoL nomenclature [20].

After data review, patients were divided between those who underwent appendectomy alone (Appendectomy group) and those who underwent completion pRHC (pRHC group). To avoid immortal time bias, baseline for the pRHC group was defined as the first date on which patients underwent pRHC, whereas baseline for the Appendectomy group was the date of appendectomy.

\section{Statistical analysis}

Variables are presented as medians with ranges or means with standard deviations (SDs), as appropriate. Differences between groups were assessed using the Chi-square test and the non-parametric Mann-Whitney test, as appropriate, due to the non-normality of data distributions, but also the ordinal nature of the patient-based HRQoL to limit assumptions and maintain consistency. Multivariable logistic regression analysis was performed to assess histopathological parameters associated with $\mathrm{LN}$ positivity at pRHC. Quantitative HRQoL data analysis was conducted to explore whether the type of surgical procedure (appendectomy vs pRHC) was associated with the reporting of HRQOL issues. All tests were 2 sided unless stated otherwise. $P<0.05$ was considered to be significant for all tests. All statistical analyses were done with the SPSS v23.0 software package (IBM SPSS Statistics, Armonk, NY, USA).

\section{Results}

Of a total of 182 patients with ANENs, 166 patients fulfilled the inclusion criteria (119 women [71.2\%]) and 47 men $[28.8 \%])$. Mean $( \pm$ SD) age at baseline was $31( \pm 16)$ years and most patients were otherwise healthy (Charlson comorbidity index $\leq 1$ in 154/166 [92.8\%] patients; Table 1) [21]. Mean $( \pm \mathrm{SD})$ overall follow-up was $50.9( \pm 54)$ months. One hundred eight patients had appendectomy alone (Appendectomy group; $n=108$ ), whereas 58 (34.9\%)
Table 1 Clinicopathological characteristics of patients diagnosed with well-differentiated appendiceal neuroendocrine neoplasms included in the study cohort at initial diagnosis $(n=166)$

\begin{tabular}{|c|c|}
\hline Patient and tumor characteristics & Number of patients (\%) \\
\hline Mean age $( \pm \mathrm{SD})^{*}$ & $31( \pm 16)$ \\
\hline \multicolumn{2}{|l|}{ Gender } \\
\hline Female & $119(71.2)$ \\
\hline Male & $47(28.8)$ \\
\hline \multicolumn{2}{|l|}{ Type/extent of surgery } \\
\hline Appendectomy alone & $108(65.1)$ \\
\hline Completion pRHC & $58(34.9)$ \\
\hline \multicolumn{2}{|l|}{ Charlson comorbidity Index } \\
\hline 0 & $138(83.1)$ \\
\hline 1 & $16(9.6)$ \\
\hline 2 & $7(4.2)$ \\
\hline 3 & $2(1.2)$ \\
\hline$\geq 4$ & $2(1.2)$ \\
\hline \multicolumn{2}{|l|}{ Tumor size } \\
\hline$<1 \mathrm{~cm}$ & $74(44.6)$ \\
\hline $1-2 \mathrm{~cm}$ & $71(42.8)$ \\
\hline$>2 \mathrm{~cm}$ & $16(9.6)$ \\
\hline unknown & $5(3)$ \\
\hline \multicolumn{2}{|l|}{ Grade } \\
\hline G1 & $144(86.7)$ \\
\hline $\mathrm{G} 2$ & $18(10.8)$ \\
\hline Unknown & $4(2.4)$ \\
\hline \multicolumn{2}{|l|}{ Location } \\
\hline Base & $18(10.8)$ \\
\hline Body & $28(16.9)$ \\
\hline Apex & $91(54.8)$ \\
\hline Unknown & $19(11.5)$ \\
\hline \multicolumn{2}{|l|}{ Mesoappendiceal invasion } \\
\hline No & $86(51.8)$ \\
\hline Yes & $76(45.8)$ \\
\hline Unknown & $4(2.4)$ \\
\hline \multicolumn{2}{|l|}{ Vascular invasion } \\
\hline No & $143(86.1)$ \\
\hline Yes & $19(11.4)$ \\
\hline Unknown & $4(2.4)$ \\
\hline \multicolumn{2}{|l|}{ Lymph vessel invasion } \\
\hline No & 147 (88.6) \\
\hline Yes & $15(9)$ \\
\hline Unknown & $4(2.4)$ \\
\hline \multicolumn{2}{|l|}{ Perineural invasion } \\
\hline No & $140(84.3)$ \\
\hline Yes & $22(15.3)$ \\
\hline Unknown & $4(2.4)$ \\
\hline
\end{tabular}

*At baseline

underwent completion pRHC following primary appendectomy (pRHC group; $n=58$; mean $( \pm \mathrm{SD}$ ) time to completion: 116,4 \pm 121.9 days) (Fig. 1). Most patients (149 [89.8\%]) had tumors $<20 \mathrm{~mm}$ in size and $71(42.8 \%)$ had tumors in the zone of $10-20 \mathrm{~mm}$. In the pRHC group, 43 patients had tumors $\leq 20 \mathrm{~mm}$, whereas 39 patients in the appendectomy group had tumors in the gray zone of 10-20 mm (Table 1). 
Fig. 1 Study flow chart

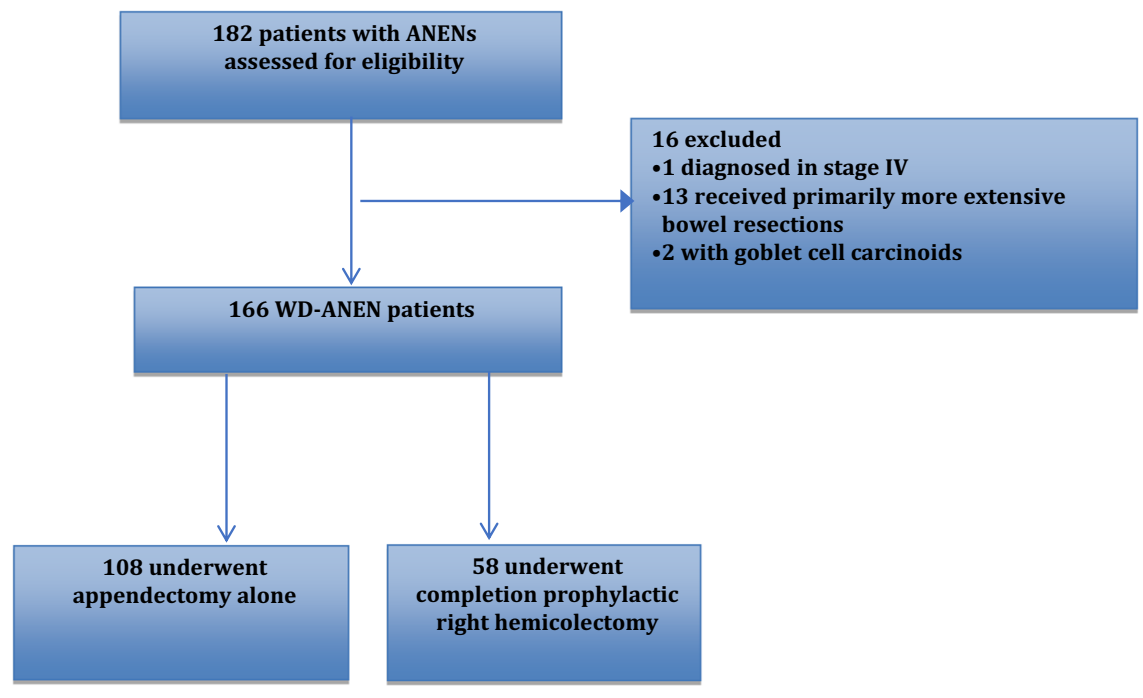

Completion pRHC was likely unecessary in $38 / 58$ patients (65.5\%; no residual disease or locoregional LN metastases); and in 34/43 patients (79.1\%) in the subset of patients with tumors $\leq 20 \mathrm{~mm}$ subjected to prophylactic surgery. On the other hand, $13 / 39$ patients $(33.3 \%)$ with tumor size $10-20 \mathrm{~mm}$ had one or more risk factors for positive LN status (such as grade 2, vascular-, lymph vessel- and/or perineural invasion), but underwent appendectomy alone. Among the investigated clinicopathological parameters used for completion pRHC, tumor size $\geq 20 \mathrm{~mm}$ was confirmed as an independent prognostic factor for $\mathrm{LN}$ positivity on multivariable logistic regression analysis (HR $=0.058$; 95\%CI:0.009-0.351; $p=0.002$; Table 2). Neither overall- nor disease-specific mortality was encountered in this series. Three patients developed a recurrence $(n=2$ in the pRHC group vs $n=1$ in the Appendectomy group; $p=$ 0.263). Among the two patients in the pRHC group who developed recurrence, one had positive $\mathrm{LN}$ at diagnosis, whereas the patient in the Appendectomy group with a recurrence had no risk factors. Two of the patients developed distant metastases found at cross-sectional imaging; one to the liver (pRHC group) and one to the bones (Appendectomy group), whereas one to locoregional LN (metachronous LN metastases; pRHC group). Importantly, none among the 13 patients in the appendectomy group with tumors $10-20 \mathrm{~mm}$ in size and one or more risk factors had residual disease or developed a recurrence at subsequent cross-sectional imaging.

Overall, 136 WD-ANEN patients (81.9\%) were subjected to postoperative cross-sectional imaging with the remaining 30 patients being discharged after surgery. In particular, 69 patients $(50.7 \%)$ had an MRI scan or less commonly a CT scan performed more than 2 years from baseline, whereas in $38(22.9 \%)$ and 16 patients $(9.6 \%)$ cross-sectional imaging was obtained more than 5- and
Table 2 Binary logistic regression model with risk assessment for positive lymph node status at completion prophylactic right hemicolectomy in patients with well-differentiated appendiceal neuroendocrine neoplasms $(n=58)$ included in this study

Prognostic factor for positive LN status at pRHC $(n=58)$

\begin{tabular}{|c|c|c|c|}
\hline & HR & $95 \% \mathrm{CI}$ & $P$ value \\
\hline Tumor size & & & 0.002 \\
\hline$\geq 20 \mathrm{~mm}$ & 1 & & \\
\hline$<20 \mathrm{~mm}$ & 0.058 & $0.009-0.351$ & \\
\hline Grade & & & 0.328 \\
\hline G1 & 1 & & \\
\hline $\mathrm{G} 2$ & 3.68 & $0.271-49.89$ & \\
\hline Location & & & 0.473 \\
\hline Base & 1 & & \\
\hline Non-base & 0.518 & $0.086-3.119$ & \\
\hline Mesoappendiceal invasion & & & 0.525 \\
\hline No & 1 & & \\
\hline Yes & 1.762 & $0.307-10.117$ & \\
\hline Vascular invasion & & & 0.853 \\
\hline No & 0.786 & $0.061-10.140$ & \\
\hline Yes & 1 & & \\
\hline Lymph vessel invasion & & & 0.091 \\
\hline No & 0.090 & $0.06-1.469$ & \\
\hline Yes & 1 & & \\
\hline Perineural invasion & & & 0.137 \\
\hline No & 0.208 & $0.26-1.652$ & \\
\hline Yes & 1 & & \\
\hline
\end{tabular}

Bold value indicates statistically significant

10-years from baseline, respectively. Two-, five- and tenyear recurrence-free survival (RFS) in patients subjected to cross-sectional imaging $(n=136)$ was $98.5 \%, 97.8 \%$ and 97.8\%, respectively (Fig. 2). 


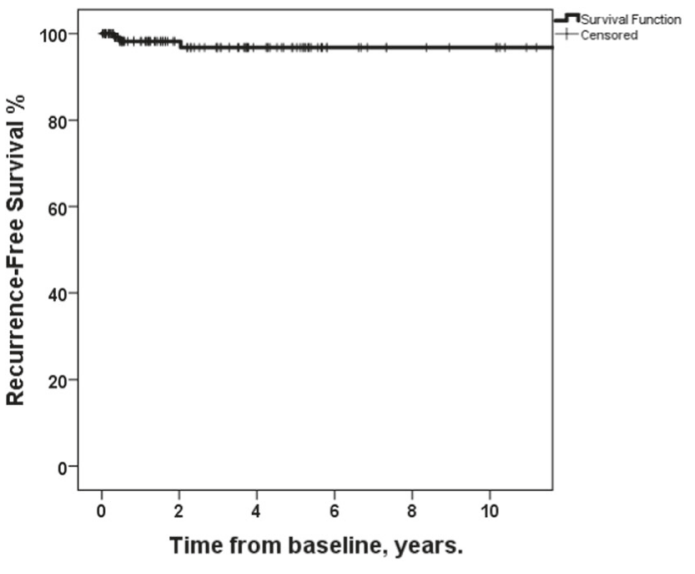

\begin{tabular}{|l|l|l|l|l|l|l|}
\hline $\begin{array}{l}\text { No. patients } \\
\text { at risk }\end{array}$ & 136 & 69 & 45 & 23 & 18 & 16 \\
\hline
\end{tabular}

Fig. 2 Recurrence-free survival in patients with well-differentiated appendiceal neuroendocrine neoplasms subjected to postoperative cross-sectional imaging $(n=136)$, commonly magnetic resonance tomography. Survival estimates assessed from baseline

With regards to other treatments, three patients in this series received somatostatin analogues after initial surgery (two patients due to recurrence). Finally, one additional patient with WD-ANEN from the initial cohort presented with liver metastasis at diagnosis and therefore was excluded from the analysis ( $3 / 180$ patients with stage IV disease at any point [1.7\%]; Fig. 1). Two patients in the pRHC group $(2 / 58 ; 3.4 \%)$ were re-operated subsequently for bowel obstruction due to postoperative adhesions, whereas re-operations due to incisional hernias were not reported during the study follow-up.

The following HRQoL issues emerged from content analysis of 79 patient responses (any change in global HRQoL/symptom scales vs none): global health status (64 [81\%]), physical-(41[51.2\%]), role-(23[29.1\%]), emotional(48 [60\%]), cognitive-(32 [40.5\%]) and social functioning (25[31.6\%]). Global HRQoL was not significantly depreciated in patients with WD-ANEN $(n=79)$ compared with age- and sex-matched healthy individuals without any abdominal surgery at their medical history (median scores [range]: $0.83[0.08-1]$ vs $0.83[0.4-1]$, respectively; $p=$ $0.929)$. However, appetite $(p=0.040)$ and diarrhea $(0.017)$ concerns were more often reported among WD-ANEN patients than healthy controls (Table 3). Among WDANEN patients that participated in the HRQoL assessment, global HRQoL was not significantly impaired in patients undergoing pRHC compared with appendectomy alone (median scores $0.79[0.25-1]$ vs $0.83[0.08-1]$, respectively; $p=0.738)$. In addition, the multivariable logistic regression model (adjusted for age and sex) applied for HRQoL analysis, did not provided any
Table 3 Comparison of Health-Related Quality of Life concerns between patients with well-differentiated appendiceal neuroendocrine tumors $(n=79)$ and age- and sex-matched individuals without any abdominal surgery at own medical history $(n=20)$

\begin{tabular}{|c|c|c|c|}
\hline HRQoL issue & $\begin{array}{l}\text { Median scores } \\
(95 \% \mathrm{CI}) \text { in WD- } \\
\text { ANEN patients } \\
(n=79)\end{array}$ & $\begin{array}{l}\text { Median scores }(95 \% \\
\text { CI) in matched } \\
\text { controls }(n=20)\end{array}$ & $P$ value \\
\hline Global HRQoL & $0.83(0.08-1)$ & $0.83(0.4-1)$ & 0.929 \\
\hline \multicolumn{4}{|l|}{ Functional issues } \\
\hline $\begin{array}{l}\text { Physical } \\
\text { functioning }\end{array}$ & $1(0.86-0.94)$ & $0.97(0.91-0.97)$ & 0.910 \\
\hline $\begin{array}{l}\text { Role } \\
\text { functioning }\end{array}$ & $1(0.87-0.95)$ & $1(0.82-0.96)$ & 0.318 \\
\hline $\begin{array}{l}\text { Emotional } \\
\text { functioning }\end{array}$ & $0.83(0.72-0.84)$ & $0.88(0.71-0.9)$ & 0.989 \\
\hline $\begin{array}{l}\text { Cognitive } \\
\text { functioning }\end{array}$ & $1(0.82-0.91)$ & $1(0.76-0.99)$ & 0.436 \\
\hline $\begin{array}{l}\text { Social } \\
\text { functioning }\end{array}$ & $1(0.82-0.92)$ & $1(0.83-0.99)$ & 0.596 \\
\hline \multicolumn{4}{|l|}{ Symptom scales } \\
\hline Fatigue & $0.22(0.21-0.34)$ & $0.33(0.25-0.46)$ & 0.117 \\
\hline Nausea & $0(0.03-0.11)$ & $0(-0.01-0.06)$ & 0.202 \\
\hline Pain & $0(0.11-0.20)$ & $0(0.03-0.16)$ & 0.286 \\
\hline Dyspnoea & $0(0.03-0.16)$ & $0(0.003-0.13)$ & 0.740 \\
\hline Insomnia & $0(0.17-0.32)$ & $0(0.01-0.29)$ & 0.641 \\
\hline Appetite & $0(0.10-0.219$ & $0(-0.01-0.08)$ & 0.040 \\
\hline Constipation & $0(0.07-0.18)$ & $0(0.01-0.27)$ & 0.298 \\
\hline Diarrhea & $0(0.13-0.25)$ & $0(-0.01-0.11)$ & 0.017 \\
\hline $\begin{array}{l}\text { Financial } \\
\text { difficulties }\end{array}$ & $0(0.06-0.18)$ & $0(-0.02-0.15)$ & 0.389 \\
\hline
\end{tabular}

Bold values indicates statistically significant

evidence of a difference in reporting of a change in or concern about global HRQoL (any vs none) between surgery types in the two groups of the study (pRHC group vs App group; $\mathrm{HR}=0.768 ; 95 \% \mathrm{CI}: 0.234-2.518 ; p=0.663$ ). However, analyses in functional and symptom scales revealed that impaired social functioning $(p=0.016)$, diarrhea $(p=0.003)$, and financial difficulties $(0.024)$ were more frequently reported in the pRHC group (Table 4). Furthermore, physical- $(p=0.066)$ and role functioning $(p=0.055)$, as well as constipation issues $(p=0.072)$ emerged in the pRHC group with marginal significance (Table 4). Diarrhea was mainly attributed to pRHC as further comparison between the Appendectomy group and the group of healthy controls did not yield any statistical significance on this particular outcome (median scores [range]: $0[0-0.33$ ] vs $0[0-0.67] ; p=0.141)$. Comparable number of patients in the pRHC and appendectomy group fulfilled the HRQoL questionnaires (49/108 [45.4\%] vs 30/ $58[51.7 \%]$, respectively). 
Table 4 Comparison of Health-Related Quality of Life concerns between patients with well-differentiated appendiceal neuroendocrine neoplasms (WD-ANEN) undergoing appendectomy alone $(n=49)$ and WD-ANEN patients undergoing completion prophylactic right hemicolectomy $(n=30)$

\begin{tabular}{|c|c|c|c|}
\hline HRQoL issue & $\begin{array}{l}\text { Median scores } \\
(95 \% \mathrm{CI}) \text { in } \\
\text { Appendectomy } \\
\text { group }(n=49)\end{array}$ & $\begin{array}{l}\text { Median scores } \\
(95 \% \mathrm{CI}) \text { in pRHC } \\
\text { group }(n=30)\end{array}$ & $P$ value \\
\hline Global HRQoL & $0.83(0.68-0.81)$ & $0.79(0.64-0.81)$ & 0.738 \\
\hline \multicolumn{4}{|l|}{ Functional issues } \\
\hline $\begin{array}{l}\text { Physical } \\
\text { functioning }\end{array}$ & $1(0.87-0.96)$ & $0.93(0.80-0.94)$ & 0.066 \\
\hline $\begin{array}{l}\text { Role } \\
\text { functioning }\end{array}$ & $1(0.91-0.98)$ & $1(0.76-0.95)$ & 0.055 \\
\hline $\begin{array}{l}\text { Emotional } \\
\text { functioning }\end{array}$ & $0.83(0.71-0.85)$ & $0.92(0.68-0.88)$ & 0.907 \\
\hline $\begin{array}{l}\text { Cognitive } \\
\text { functioning }\end{array}$ & $1(0.82-0.94)$ & $1(0.76-0.93)$ & 0.443 \\
\hline $\begin{array}{l}\text { Social } \\
\text { functioning }\end{array}$ & $1(0.85-0.97)$ & $1(0.70-0.90)$ & 0.016 \\
\hline \multicolumn{4}{|l|}{ Symptom scales } \\
\hline Fatigue & $0.22(0.17-0.28)$ & $0.33(0.22-0.48)$ & 0.182 \\
\hline Nausea & $0(0.02-0.08)$ & $0(0.02-0.19)$ & 0.407 \\
\hline Pain & $0(0.07-0.17)$ & $0.17(0.12-0.29)$ & 0.137 \\
\hline Dyspnoea & $0(0.01-0.13)$ & $0(0.02-0.17)$ & 0.290 \\
\hline Insomnia & $0(0.14-0.3)$ & $0(0.15-0.44)$ & 0.406 \\
\hline Appetite & $0(0.09-0.22)$ & $0(0.03-0.28)$ & 0.415 \\
\hline Constipation & $0(0.03-0.15)$ & $0(0.08-0.3)$ & 0.072 \\
\hline Diarrhea & $0(0.06-0.17)$ & $0.33(0.2-0.42)$ & 0.003 \\
\hline $\begin{array}{l}\text { Financial } \\
\text { difficulties }\end{array}$ & $0(0.08-0.32)$ & $0(0.02-0.17)$ & 0.024 \\
\hline
\end{tabular}

Bold values indicates statistically significant

\section{Discussion}

In the present study, we assessed in a multicenter setting, outcomes of patients with WD-ANENs after completion pRHC compared with appendectomy alone. A prophylactic surgical approach based on contemporary criteria in this series suggested that pRHC was probably an overtreatment in approximately two-thirds of the patients undergoing pRHC. Appendectomy alone would have been a curative measure in $84 \%$ of all patients and in $92.5 \%$ of patients with tumors $<20 \mathrm{~mm}$ in size. Among patients selected for completion $\mathrm{pRHC}$ with tumors $<20 \mathrm{~mm}$ in size and one or more risk factors favouring a pRHC, approximately one fifth will be found to have $\mathrm{LN}$ metastases at reoperation. In addition, no mortality and very low recurrence rate were evident in our study, questioning the prognostic impact of LN involvement at pRHC. Most WD-ANEN patients in this series (81.9\%) were subjected to postoperative cross-sectional imaging, commonly MRI, and exhibited favorable RFS figures at 2-, 5- and 10-year RFS as high as $98.5 \%, 97.8 \%$, and $97.8 \%$, respectively. Although we found no difference in global HRQoL between WD-ANEN patients and age-/ sex-matched healthy controls, impaired social functioning, diarrhea, and financial difficulties were more frequently reported in patients undergoing completion pRHC. Furthermore, physical and role functioning, as well as constipation issues emerged in the pRHC group with marginal significance.

Traditionally, a tumor size $>20 \mathrm{~mm}$ constitutes a general indication for completion $\mathrm{pRHC}$ based on the seminal paper in the field by Moertel et al. [22]. This parameter was subsequently validated in numerous studies and recent meta-analyses and also confirmed in the multivariable logistic regression analysis of the present study [2, 5, 8, 9, 23-26]. ENETS guidelines have also considered tumor size $>20 \mathrm{~mm}$ to guide the extent of surgery in patients with WD-ANENs. For tumor size $10-20 \mathrm{~mm}$, various histopathological parameters have been applied to identify right candidates for completion pRHC although not fully validated. In particular, the location of the primary tumor in the base of the appendix, grade 2, mesoappendix, vascular, lymph vessel, and perineural invasion has been implied as a risk factors for synchronous $\mathrm{LN}$ metastases necessitating completion pRHC [7, 8, 13, 27, 28]. However, these factors were not confirmed in our study with respect to $\mathrm{LN}$ metastases prediction. The reasons that our data could not confirm the role of certain histopathological parameters, for example that of lymphovascular invasion to predict nodal involvement may be multifactorial, including lack of centralized pathology review, but also limitations inherent to the nature of databases, such as the Surveillance, Epidemiology, and End Results Program (SEER) and the National Cancer Database (NCDB) with unrecorded variables, underreported and incomplete data, NEN heterogeneity and finally the inclusion of goblet cell appendiceal tumors and tumors of mixed histopathology in other studies.

Several recent studies have implied a low-malignant tumor biology and challenged the clinical relevance of indolent positive $\mathrm{LN}$ at $\mathrm{pRHC}$ as it appears to exert no major effect on overall survival [2, 12, 13, 27, 29, 30]. However, to date there is no definite data regarding the long-term outcomes of this patient group. Three patients only in our series demonstrated disease recurrence, two of whom underwent a pRHC according to ENETS guidelines. Overall, the prevalence of stage IV disease at any point in the initial cohort was as low as $1.7 \%$ whereas all patients were alive at last follow-up, in line with other recent studies $[2,31]$. The 50-month mean follow-up period of patients in this cohort and the relatively small subset of patients followed longer than 5- and 10-years respectively may limit our conclusions on long-term patient outcomes. However, this follow-up is one of the longest reported in WD-ANEN 
patients after correction for potential immortal time bias. Cross-sectional imaging confirmation of disease status in most patients $(81.9 \%)$ was one of the main strengths of this study as well as the availability of imaging data in the small subset of patients with risk factors who did not have pRHC and also that of prospective MRI data in patients with follow-up $>10$ years.

With regards to HRQoL analysis, the reliability and validity of the employed HRQoL instruments in WDANEN patients assessing the treatment option of pRHC may be more straight-forward, than in other aggressive cancer forms where somatic manifestations of psychological distress might be attributed to the tumor itself rather than the treatment of it. As only three patients developed recurrence and no systemic treatments were given to almost all WDANEN patients, HRQoL differences between the Appendectomy- and the pRHC group could be mainly attributed to the type/extent of the surgical procedure undertaken.

This study has some limitations, including the retrospective nature of the risk assessment analysis for $\mathrm{LN}$ metastases and the lack of centralized pathology review that mainly concerns interstudy concordance for tumor size and that of other histopathological parameters. However, histopathological review was conducted by dedicated specialists in the involved ENETS centers and prospectively collected MRI data were used to accurately define disease status in the longterm. In addition, as our analysis was based on data from patients referred to specialized centers, referral bias might have skewed the results. Although not all patients of this cohort participated in the HRQoL analysis, a significant number from each group fulfilled the HRQoL questionnaires. Nevertheless, long-term evaluation mainly with MRI at 5 and 10 years of follow-up was available for a minority of patients, thus inferences on long-term recurrence should be interpreted with caution. The results from multivariable analysis on a relatively rare tumor entity suggests only size $>20 \mathrm{mmm}$ is a significant factor predicting abnormal post-operative pathology; therefore, other features such as tumor location in the base of the appendix, grade 2, mesoappendix, vascular, lymph vessel, and perineural invasion in 1-2 cm lesions should not be indications for completion pRHC. In addition, functional HRQoL concerns and diarrhea may affect a substantial proportion of patients undergoing prophylactic surgery. To our knowledge, this study is the first to analyze HRQoL issues among patients with WD-ANEN and among few that assess long-term outcomes in this patient group.

In conclusion, our study demonstrates that patients with WD-ANENs whose surgical management is based on contemporary criteria for a prophylactic surgical approach are subjected to excessive surgery and exhibit functional HRQoL concerns and development of diarrhea. In light of our results, the value of prophylactic surgery should probably be reconsidered and the appropriateness of a more conservative approach at least in tumors $<20 \mathrm{~mm}$ in size should be employed. As reliable biomarkers allowing targeted preventive surgery are not currently available in WDANENs, appendectomy alone may be as safe in terms of survival outcomes in almost all patients and could lead to a reduction of overtreatment and related adverse effects. In the era of personalized medicine, ANEN patients and involved physicians should consider the implications of WD-ANEN diagnosis as a low-malignant entity and the implementation of appropriate surveillance strategies to balance any negative surgery-related outcomes.

Funding KD was supported by the Royal Swedish Academy of Sciences. The other authors of the study have not received any funding. Open access funding provided by Örebro University.

Author contributions KIA and GK contributed equally to this study. KD and GK had full access to all the data in the study and take responsibility for the integrity of the data and the accuracy of the data analysis.

\section{Compliance with ethical standards}

Conflict of interest The authors declare that they have no conflict of interest.

Ethical approval All procedures performed in studies involving human participants were in accordance with the ethical standards of the institutional and/or national research committee and with the 1964 Helsinki declaration and its later amendments or comparable ethical standards. In UK collaborating centers, the study was officially registered as an audit.

Informed consent Informed consent was obtained from all individual participants included in the study.

Publisher's note Springer Nature remains neutral with regard to jurisdictional claims in published maps and institutional affiliations.

Open Access This article is licensed under a Creative Commons Attribution 4.0 International License, which permits use, sharing, adaptation, distribution and reproduction in any medium or format, as long as you give appropriate credit to the original author(s) and the source, provide a link to the Creative Commons license, and indicate if changes were made. The images or other third party material in this article are included in the article's Creative Commons license, unless indicated otherwise in a credit line to the material. If material is not included in the article's Creative Commons license and your intended use is not permitted by statutory regulation or exceeds the permitted use, you will need to obtain permission directly from the copyright holder. To view a copy of this license, visit http://creativecommons. org/licenses/by/4.0/.

\section{References}

1. A. Dasari, C. Shen, D. Halperin, B. Zhao, S. Zhou, Y. Xu, T. Shih, J.C. Yao, Trends in the Incidence, prevalence, and survival outcomes in patients with neuroendocrine tumors in the United States. JAMA Oncol. 3(10), 1335-1342 (2017). https://doi.org/10. 1001/jamaoncol.2017.0589 
2. N. Pawa, A.K. Clift, H. Osmani, P. Drymousis, A. Cichocki, R. Flora, R. Goldin, D. Patsouras, A. Baird, A. Malczewska, J. Kinross, O. Faiz, A. Antoniou, H. Wasan, G.A. Kaltsas, A. Darzi, J.B. Cwikla, A. Frilling, Surgical management of patients with neuroendocrine neoplasms of the appendix: appendectomy or more. Neuroendocrinology. 106(3), 242-251 (2018). https://doi. org $/ 10.1159 / 000478742$

3. K.I. Alexandraki, G.A. Kaltsas, S. Grozinsky-Glasberg, E. Chatzellis, A.B. Grossman, Appendiceal neuroendocrine neoplasms: diagnosis and management. Endocr. Relat. Cancer. 23(1), R27-41 (2016). https://doi.org/10.1530/ERC-15-0310

4. A. Brigic, S. Sakuma, R.E. Lovegrove, P. Bassett, O. Faiz, S.K. Clark, N. Mortensen, R.H. Kennedy, A prospective case control study of functional outcomes and related quality of life after colectomy for neoplasia. Int. J. Colorectal. Dis. 32(6), 777-787 (2017). https://doi.org/10.1007/s00384-016-2714-3

5. U.F. Pape, B. Niederle, F. Costa, D. Gross, F. Kelestimur, R. Kianmanesh, U. Knigge, K. Oberg, M. Pavel, A. Perren, C. Toumpanakis, J. O'Connor, E. Krenning, N. Reed, D. O'Toole, ENETS consensus guidelines for neuroendocrine neoplasms of the appendix (excluding goblet cell carcinomas). Neuroendocrinology. 103(2), 144-152 (2016). https://doi.org/10.1159/000443165. Vienna Consensus Conference

6. T. Bednarczuk, M. Bolanowski, A. Zemczak, A. Baldys-Waligorska, J. Blicharz-Dorniak, A. Boratyn-Nowicka, M. Borowska, A. Cichocki, J.B. Cwikla, M. Falconi, W. Foltyn, D. Handkiewicz-Junak, A. Hubalewska-Dydejczyk, B. Jarzab, R. Junik, D. Kajdaniuk, G. Kaminski, A. Kolasinska-Cwikla, A. Kowalska, R. Krol, L. Krolicki, J. Kunikowska, K. Kusnierz, P. Lampe, D. Lange, A. Lewczuk-Myslicka, A. Lewinski, M. Lipinski, M. Londzin-Olesik, B. Marek, A. Nasierowska-Guttmejer, E. Nowakowska-Dulawa, J. Palucki, J. Pilch-Kowalczyk, V. Rosiek, M. Ruchala, L. Sieminska, A. Sowa-Staszczak, T. Starzynska, K. Steinhof-Radwanska, J. Strzelczyk, K. Sworczak, A. Syrenicz, A. Szawlowski, M. Szczepkowski, E. Wachula, W. Zajecki, W. Zgliczynski, B. Kos-Kudla, Neuroendocrine neoplasms of the small intestine and appendix - management guidelines (recommended by the Polish Network of Neuroendocrine Tumours). Endokrynol. Pol. 68(2), 223-236 (2017). https://doi.org/10.5603/ EP.2017.0018

7. M. Galanopoulos, R. McFadyen, I. Drami, R. Naik, N. Evans, T. V. Luong, J. Watkins, M. Caplin, C. Toumpanakis, Challenging the current risk factors of appendiceal neuroendocrine neoplasms: can they accurately predict local lymph nodal invasion? results from a large case series. Neuroendocrinology. 109(2), 179-186 (2019). https://doi.org/10.1159/000499381

8. K. Daskalakis, K. Alexandraki, E. Kassi, M. Tsoli, A. Angelousi, A. Ragkousi, G. Kaltsas, The risk of lymph node metastases and their impact on survival in patients with appendiceal neuroendocrine neoplasms: a systematic review and meta-analysis of adult and paediatric patients. Endocrine (2019). https://doi.org/10.1007/ s12020-019-02072-y

9. C. Ricci, C. Ingaldi, L. Alberici, N. Brighi, D. Santini, C. Mosconi, V. Ambrosini, D. Campana, F. Minni, R. Casadei, Histopathological diagnosis of appendiceal neuroendocrine neoplasms: when to perform a right hemicolectomy? A systematic review and meta-analysis. Endocrine. 66(3), 460-466 (2019). https://doi.org/ 10.1007/s12020-019-01984-Z

10. N. Brighi, S. La Rosa, G. Rossi, F. Grillo, S. Pusceddu, M. Rinzivillo, F. Spada, S. Tafuto, S. Massironi, A. Faggiano, L. Antonuzzo, D. Santini, F. Sessa, R. Maragliano, F. Gelsomino, M. Albertelli, C. Vernieri, F. Panzuto, N. Fazio, C. De Divitiis, G. Lamberti, A. Colao, G.D. Fave, D. Campana, Morphological factors related to nodal metastases in neuroendocrine tumors of the appendix: a multicentric retrospective study. Ann. Surg.
271(3), 527-533 (2020). https://doi.org/10.1097/SLA. 0000000000002939

11. B. Rault-Petit, C. Do Cao, S. Guyetant, R. Guimbaud, V. Rohmer, C. Julie, E. Baudin, B. Goichot, R. Coriat, A. Tabarin, J. Ramos, P. Goudet, V. Hervieu, J.Y. Scoazec, T. Walter, Current management and predictive factors of lymph node metastasis of appendix neuroendocrine tumors: a national study from the french group of endocrine tumors (GTE). Ann. Surg. 270(1), 165-171 (2019). https://doi.org/10.1097/SLA.0000000000002736

12. A. Ciarrocchi, R. Pietroletti, F. Carlei, S. Necozione, G. Amicucci, Propensity adjusted appraisal of the surgical strategy for appendiceal carcinoids. Tech. Coloproctol. 19(1), 35-41 (2015). https:// doi.org/10.1007/s10151-014-1249-2

13. Z.M. Bamboat, D.L. Berger, Is right hemicolectomy for $2.0-\mathrm{cm}$ appendiceal carcinoids justified? Arch. Surg. 141(4), 349-352 (2006). https://doi.org/10.1001/archsurg.141.4.349. discussion 352

14. N.K. Aaronson, S. Ahmedzai, B. Bergman, M. Bullinger, A. Cull, N.J. Duez, A. Filiberti, H. Flechtner, S.B. Fleishman, J.C. de Haes et al. The European organization for research and treatment of cancer QLQ-C30: a quality-of-life instrument for use in international clinical trials in oncology. J. Natl. Cancer Inst. 85(5), 365-376 (1993). https://doi.org/10.1093/jnci/85.5.365

15. E. von Elm, D.G. Altman, M. Egger, S.J. Pocock, P.C. Gotzsche, J.P. Vandenbroucke, S. Initiative, The strengthening the reporting of observational studies in epidemiology (STROBE) statement: guidelines for reporting observational studies. J. Clin. Epidemiol. 61(4), 344-349 (2008). https://doi.org/10.1016/j.jclinepi.2007.11. 008

16. C. Virgone, G. Cecchetto, R. Alaggio, A. Ferrari, G. Bisogno, M. Conte, A. Inserra, A.M. Fagnani, P. Indolfi, N. Salfi, P. Dall'Igna, Appendiceal neuroendocrine tumours in childhood: Italian TREP project. J. Pediatr. Gastroenterol. Nutr. 58(3), 333-338 (2014). https://doi.org/10.1097/MPG.0000000000000217

17. R. Arnold, Y.J. Chen, F. Costa, M. Falconi, D. Gross, A.B. Grossman, R. Hyrdel, B. Kos-Kudla, R. Salazar, U. Plockinger, ENETS consensus guidelines for the standards of care in neuroendocrine tumors: follow-up and documentation. Neuroendocrinology. 90(2), 227-233 (2009). https://doi.org/10.1159/ 000225952. Mallorca Consensus Conference, p., European Neuroendocrine Tumor, S.

18. R.V. Lloyd, R.Y. Osamura, G. Klöppel, WHO classification of tumours of endocrine organs, WHO Classification of Tumours, 4th ed, vol. 10 (2017) pp 209-239

19. D.E.E. Gress, F. Greene, M. Washington, E. Asare, J. Brierley, Principles of Cancer Staging. AJCC Cancer Staging Manual, 8th ed. (Springer, New York, 2017)

20. K. Cocks, M.T. King, G. Velikova, M. Martyn St-James, P.M. Fayers, J.M. Brown, Evidence-based guidelines for determination of sample size and interpretation of the European Organisation for the Research and Treatment of Cancer Quality of Life Questionnaire Core 30. J. Clin. Oncol. 29(1), 89-96 (2011). https://doi. org/10.1200/JCO.2010.28.0107

21. M.E. Charlson, P. Pompei, K.L. Ales, C.R. MacKenzie, A new method of classifying prognostic comorbidity in longitudinal studies: development and validation. J. Chronic Dis. 40(5), 373-383 (1987). https://doi.org/10.1016/0021-9681(87)90171-8

22. C.G. Moertel, L.H. Weiland, D.M. Nagorney, M.B. Dockerty, Carcinoid tumor of the appendix: treatment and prognosis. N. Engl. J. Med. 317(27), 1699-1701 (1987). https://doi.org/10. 1056/NEJM198712313172704

23. V. Tchana-Sato, O. Detry, M. Polus, A. Thiry, B. Detroz, S. Maweja, E. Hamoir, T. Defechereux, C. Coimbra, A. De Roover, M. Meurisse, P. Honore, Carcinoid tumor of the appendix: a consecutive series from 1237 appendectomies. World J. 
Gastroenterol. 12(41), 6699-6701 (2006). https://doi.org/10. 3748/wjg.v12.i41.6699

24. M.E. O'Donnell, J. Carson, W.I. Garstin, Surgical treatment of malignant carcinoid tumours of the appendix. Int. J. Clin. Pract. 61 (3), 431-437 (2007). https://doi.org/10.1111/j.1742-1241.2006. 00875.x

25. A. Roggo, W.C. Wood, L.W. Ottinger, Carcinoid tumors of the appendix. Ann. Surg. 217(4), 385-390 (1993). https://doi.org/10. 1097/00000658-199304000-00010

26. B. Stinner, O. Kisker, A. Zielke, M. Rothmund, Surgical management for carcinoid tumors of small bowel, appendix, colon, and rectum. World J. Surg. 20(2), 183-188 (1996). https://doi.org/ $10.1007 / \mathrm{s} 002689900028$

27. D.A. Kleiman, B. Finnerty, T. Beninato, R. Zarnegar, G. Nandakumar, T.J. Fahey 3rd, S.W. Lee, Features associated with metastases among well-differentiated neuroendocrine (carcinoid) tumors of the appendix: the significance of small vessel invasion in addition to size. Dis. Colon. Rectum. 58(12), 1137-1143 (2015). https://doi.org/10.1097/DCR.0000000000000492
28. A.M. Blakely, M. Raoof, P.H.G. Ituarte, Y. Fong, G. Singh, B. Lee, Lymphovascular invasion is associated with lymph node involvement in small appendiceal neuroendocrine tumors. Ann. Surg. Oncol. 26(12), 4008-4015 (2019). https://doi.org/10.1245/ s10434-019-07637-9

29. J.T. Mullen, D.M. Savarese, Carcinoid tumors of the appendix: a population-based study. J. Surg. Oncol. 104(1), 41-44 (2011). https://doi.org/10.1002/jso.21888

30. G. de Lambert, H. Lardy, H. Martelli, D. Orbach, F. Gauthier, F. Guerin, Surgical management of neuroendocrine tumors of the appendix in children and adolescents: a retrospective french multicenter study of 114 cases. Pediatr. Blood Cancer 63(4), 598-603 (2016). https://doi.org/10.1002/pbc.25823

31. T. Steffen, S.M. Ebinger, R. Warschkow, C. Luthi, B.M. Schmied, T. Clerici, Long-term survival is not impaired after the complete resection of neuroendocrine tumors of the appendix. World J. Surg. 39(11), 2670-2676 (2015). https://doi.org/10.1007/s00268$015-3164-8$

\section{Affiliations}

\section{Krystallenia I. Alexandraki ${ }^{1} \cdot$ Gregory Kaltsas $^{1} \cdot$ Simona Grozinsky-Glasberg $^{2} \cdot$ Kira Oleinikov $^{2} \cdot$ Beata Kos-Kudła $^{3}$. Angelika Kogut $^{3}$ - Rajaventhan Srirajaskanthan ${ }^{4,5} \cdot$ Michail Pizanias $^{6} \cdot$ Kalliopi-Anna Poulia $^{7} \cdot$ Clara Ferreira $^{8}$. Martin O. Weickert ${ }^{9,10,11} \cdot$ Kosmas Daskalakis (iD ${ }^{1,12}$}

1 Endocrine Oncology Unit, 1st Department of Propaupedic Internal Medicine, Laiko Hospital, National and Kapodistrian University of Athens, Athens, Greece

2 Neuroendocrine Tumour Unit, ENETS CoE, Endocrinology and Metabolism Department, Hadassah-Hebrew University Medical Center, Jerusalem, Israel

3 Department of Endocrinology and Neuroendocrine Neoplasms, Department of Endocrinology and Pathophysiology, Medical University of Silesia, Katowice, Poland

4 ENETS Centre of Excellence, Neuroendocrine Tumour Unit, King's College Hospital, London SE5 9RS, UK

5 Department of Gastroenterology, King's College Hospital, London SE5 9RS, UK

6 Department of Liver Transplantation, Hepatobiliary Pancreatic Surgery, King's Healthcare Partners, King's College Hospital, NHS FT, Institute of Liver Studies, Denmark Hill, London, UK
7 Department of Nutrition, Laiko General Hospital, Athens, Greece

8 Department of Nuclear Medicine, University Hospitals Coventry and Warwickshire NHS Trust, Coventry, UK

9 The ARDEN NET Centre, European Neuroendocrine Tumour Society (ENETS) Centre of Excellence (CoE), University Hospitals Coventry and Warwickshire NHS Trust, Coventry, UK

10 Clinical Sciences Research Laboratories, Warwick Medical School, University of Warwick, University Hospital, Coventry, UK

11 Centre of Applied Biological \& Exercise Sciences, Faculty of Health \& Life Sciences, Coventry University, Coventry, UK

12 Department of Surgery, Faculty of Medicine and Health, Örebro University, Örebro, Sweden 